\title{
The Research of Inside and Outside Class Evaluation System to Private Colleges Sports Curriculum
}

\author{
Xingwei GUO \& Dawei ZHANG \& Hong YANG \\ Changchun Guanghua School, Changchun, China
}

\begin{abstract}
Build colleges sports curriculum integration teaching model is a systematic and complicated project. In the process of specific implementation, correctly handle the relationship between the each link is the key. This article in view of the "integration" teaching pattern of physical course evaluation system in the process of the discussion, put forward the new principle and scheme.
\end{abstract}

KEYWORD: Inside and outside Class; Evaluation system; Sports curriculum

\section{INTRODUCTION}

Physical education is a lifelong education, with the continuous development of society, modern sports is change accordingly, not only requires college students age, physiological and psychological characteristics, but also to have health, entertainment, sports and other education function, which requires the physical education curriculum teaching and extracurricular physical exercise in organic union, is the physical education curriculum "class inside and outside integration" teaching mode. This kind of teaching mode is emerging in the sports teaching in universities in China in recent years a new model, its characteristic is the sports teaching and extracurricular physical exercise in harmony as a whole; The close combination of theory and practice: The effective combination of school sports and health education. It is worth noting that the sports lesson "integration" in the concrete implementation of the teaching process, to correctly handle the relationship between each link, grasp the classroom teaching, extracurricular exercise, the relationship between curriculum evaluation is critical. Only do it to support each other, influence each other, complement each other can be together as a whole to achieve the overall goal of the new physical education curriculum, teaching mode can be carried out in real class inside and outside integration. Based on physical education curriculum "integration" teaching model in the process of curriculum evaluation system discussion.

\section{TRADITIONAL WAY OF EVALUATION}

Teaching evaluation is based on the teaching goal of teaching process and results of the necessary value judgment, aims at a comprehensive service for the teaching. Physical education teaching evaluation is a key link in the process of physical education curriculum, the rationalization of college PE course learning assessment, to participate in students' learning play a role, can effectively improve the effect of physical education curriculum teaching.

At present, China's colleges and universities are divided into various types, a key university, ordinary undergraduate course colleges and universities and vocational colleges, and so on. And in the midst of all types of school, no doubt, have set up the physical education, some colleges and universities of physical education, a corresponding appraisal system have been established, and a large part only to physical education as a kind of amateur activities out of class and didn't get enough attention. The conventional way of teaching evaluation is to check the teaching lesson plans, whether to organize and implement according to the teaching plan.

This way of teaching evaluation, therefore, is not true about sports teaching to carry on the quantitative management, not to the teacher's performance appraisal, is not conducive to motivate the broad masses of sports teacher's work enthusiasm. 


\section{THE REQUIREMENTS OF EVALUATION SYSTEM}

Due to all different types of colleges and universities sports curriculum, teachers, in view of the teaching object is different, and the teaching condition is different, so the corresponding appraisal system should be flexible according to the actual situation of the specific design and master, can't take a size fits, should meet the following requirements.

\subsection{Objectivity principle}

In physical education teaching evaluation, whether it's position on the standards for students, should comply with the objective reality of the sports teaching, but also has a reasonable way and method. To really do not have a subjective or mixed with personal feelings, objective, fair and reasonable, want to reflect determine correct and reasonable evaluation targets and standards.

\subsection{Integrity principle}

First of all, should be aimed at a specific physical education teaching in colleges of in-depth investigation and study, from teachers to students, from the field to the facilities, from teaching plan to lesson notes, as well as the most important of the talent training scheme, etc., as a whole to set up the content and standard of evaluation system, not to point with surface, and to do comprehensive and accurate. Second, pay attention to the evaluation system of gradation. Due to the teaching goal has the characteristics of multiplicity, according to different students' evaluation system is also different, so pay attention to the arrangement of teaching evaluation system of primary and secondary relations.

\subsection{Instructional principle}

Teaching evaluation is not only the purpose of improving the teaching of a school environment, at the same time, it has important reference significance for other similar institutions. On the one hand, it can evaluate the stand or fall of the whole teaching activities of a certain colleges, on the other hand, it will certainly put forward rationalization suggestion, and evaluation standard to do adjust measures to local conditions, reasonable, prevent not only evaluation guidance, or guidance not only evaluation.

\subsection{Scientific principle}

Scientific principle refers to the evaluation criteria, evaluation process and the method to its scientific nature. First of all, evaluation standard and evaluation content should be determined, according to the target system of "curriculum standard", according to a number of field goals, determine the reasonable evaluation standard. Evaluation using a variety of evaluation methods, such as process evaluation with summative evaluation, qualitative and quantitative evaluation method, according to the unified standard or scale analysis, measure the learning effect. Second, the evaluation of measuring accuracy, make it has a certain effect and credibility.

\section{THE METHOD TO ESTABLISH EVALUATION SYSTEM}

\section{1 establishing classroom teaching evaluation}

The purpose of evaluation is by focusing on developing evaluation to promote the continuous improvement of the teaching work. Teachers' teaching ability embodies in classroom teaching, and classroom teaching evaluation from the following several aspects:

1. With \"the health first, to promote all-round development of students $\backslash$ " as the teaching goal;

2. The choice of scientific and reasonable teaching content;

3. The reasonable teaching process structure, highlighting, difficult point properly handled;

4. Use a variety of forms of teaching methods, and innovation;

5. Complete the course task and achieve the teaching effect.

\subsection{Construct the evaluation form}

The present teaching evaluation form mainly adopts the form of self assessment of the teachers and students evaluation, in addition to this, we can also take other forms of assessment, such as peer evaluation, expert evaluation and the analysis of student achievement, and so on. According to the evaluation of the curriculum standard requirement and the actual situation, in view of the professional quality and classroom teaching content system of appropriate scale, the combination of quantitative evaluation and qualitative evaluation.

\subsection{The learning effect evaluation for students}

On students' study effect evaluation mainly from whether students can adapt to society and their own physical and mental health perspective, using the methods of qualitative and evaluation, the emphasis on evaluation of students' sports technology, the improvement and development potential. Need to set up the following aspects of content:

One is to establish the purpose of learning evaluation. Through understanding the students' learning situation and daily performance, determine whether they achieve the desired learning objectives. 
By analyzing the deficiency of students in learning and the reason, according to their aptitude, improving teaching methods in a timely manner. Can learn new knowledge constantly improve motivation, model, and to encourage and promote the students' progress and development. Second, evaluation content include physical ability, knowledge and skills, learning attitude, improvement, affective expression and spirit of cooperation.

\section{IMPLEMENTATION PLAN}

To build a comprehensive, complete process, hit a new sports teaching evaluation system, also accord with "class standard", "evaluation for the all-round development of students" concept, and to comply with the school sports teaching outline lifted up his eyes to be mentioned in the "evaluation should be based on the teaching goal, pay attention to students' learning evaluation purpose, attitude and a sense of cooperation, pay attention to the evaluation of students' imagination and creativity". This paper adopts the following concrete implementation plan.

\subsection{Performance evaluation of college students}

\subsubsection{Basic module - required content}

(1)Health education theory lecture: health education theory should focus on the content of the common health related to physical education and health care knowledge, and can include health way of life, reasonable diet and nutrition, adolescent health, safety, education, sports trauma prevention and treatment, etc., some content can be integrated into the teaching of sports practice teaching.

(2)The track and field class project completed: running, jumping, item 3 (with quality appraisal table).

(3)The gymnastics class projects: support, climbing, trailer, curvet, etc.

(2), (3) the class project in the teaching, should not be too much emphasis on systematic, integrity and fairness of the movement technology, can use the game or other, mainly school-based professional characteristics of teaching forms of exercise. Encourage teachers' innovation, through the combination and arrangement, design students interested in the comprehensive practice, but it must be to improve endurance, strength and speed The development of the three basic physical quality. Schools according to the specific circumstances, to choose at least two items from it. In imparting the basic skills and simple tactics at the same time, according to the specific situation of the students, to reduce the difficulty and transformation rules, more adversarial game or teaching. At the same time to cultivate the students' interpersonal and communication skills, teamwork spirit and competitive consciousness.

\subsubsection{Develops the content of module - option}

In order to meet the student individuality development and the needs of different health level, in the second year, should be to promote the students' physical and mental health, cultivate aesthetic ability, suitable for recreational sports, skills and methods as to expand the option in the module content. Specific as follows:

(1)aerobics, aerobics, sports dance...

(2)the table tennis, badminton...

(3)care, gymnastics, medical gymnastics, the correction. (the content of this series is open for due to illness or disability student project).

(4)according to the professional characteristics to the schools, the appropriate choice of emerging class sports or ethnic folk sports.

\subsection{After-class evaluation}

Daily sports extracurricular student record. Morning exercise, large recess activities, the lesson hold, activity, comprehensive activities, etc. Evaluation is not a one-off or intermittent, but for each student activities for a period of interest, the process of physical development track. In extracurricular activities, according to the teachers' specialty and school hardware facilities to open all kinds of activities of interest groups, to provide students' specialty development platform.

\subsection{The final evaluation}

Final grade comprehensive evaluation according to the requirements of the health standards to the reality of students, and then combines the actual conditions of the school, from sports participation, skills, physical, psychological and social adaptation ability, and other areas of the five objectives, evaluation of student performance were summarized. Is given priority to with grades, the evaluation of the final test for auxiliary methods, according to sports participation (10\%), skills $(10 \%)$, body $(10 \%)$, psychological and social adaptation ability $(10 \%)$, $(10 \%)$, grades $(30 \%)$, a comprehensive evaluation $(20 \%)$ of total points overall physical quality comprehensive evaluation of students.

\section{CONCLUSION}

In this paper, the physical education curriculum "class inside and outside the integrated teaching 
mode" course evaluation system in the process of the discussion, the analysis of the disadvantages of the traditional way of physical education teaching evaluation, put forward to establish the requirements of the evaluation system of physical education activities and methods. It is found that, by establishing new sports "class inside and outside the integrated evaluation system, on the one hand, can promote the continuous improvement of classroom teaching and improve. Classroom teaching is to serve the development of the students, the value of physical education and health classroom teaching is embodied in the students. , on the other hand, established the subject status of students, respect students' individual character development, meet the needs of the students' interest and potential development, and constantly guide students actively using autonomous, inquiry and cooperative learning method, strengthen students' application knowledge, using the skills and the ability to adapt to social development.

\section{REFERENCES}

[1] Dengsong Zhou,Lin Li. Discussion on Humanization in Teaching of Physical Education, SPOT SCIENCE, 2002,22(5). 